\title{
Measurements of Emission Factors of PM2.5, OC, EC, and BC for Household Stoves of Coal Combustion in China
}

ARTICLE in ATMOSPHERIC ENVIRONMENT · MAY 2015

Impact Factor: 3.06 · DOI: 10.1016/j.atmosenv.2015.03.023

DOWNLOADS

26
VIEWS

42

6 AUTHORS, INCLUDING:

\section{Chongguo Tian}

Chinese Academy of Sciences

42 PUBLICATIONS 207 CITATIONS

SEE PROFILE

Jun Li

Chinese Academy of Sciences 167 PUBLICATIONS $\quad 2,670$ CITATIONS

SEE PROFILE
Yanli Feng

Shanghai University

23 PUBLICATIONS 671 CITATIONS

SEE PROFILE

Gan Zhang

Chinese Academy of Sciences

303 PUBLICATIONS 6,473 CITATIONS

SEE PROFILE 


\title{
Measurements of emission factors of $\mathrm{PM}_{2.5}, \mathrm{OC}, \mathrm{EC}$, and $\mathrm{BC}$ for household stoves of coal combustion in China
}

\author{
Yingjun Chen ${ }^{a}$, Chongguo Tian ${ }^{\mathrm{a}, *}$, Yanli Feng ${ }^{\mathrm{b},{ }^{* *}}$, Guorui Zhi ${ }^{\mathrm{c}}$, Jun Li ${ }^{\mathrm{d}}$, Gan Zhang ${ }^{\mathrm{d}}$ \\ ${ }^{a}$ Key Laboratory of Coastal Environmental Processes and Ecological Remediation, Yantai Institute of Coastal Zone Research, Chinese Academy of Sciences, \\ Yantai 264003, China \\ ${ }^{\mathrm{b}}$ Institute of Environmental Pollution and Health, School of Environmental and Chemical Engineering, Shanghai University, Shanghai 200444, China \\ ${ }^{c}$ Chinese Research Academy of Environmental Sciences, Beijing 100012, China \\ d State Key Laboratory of Organic Geochemistry, Guangzhou Institute of Geochemistry, Chinese Academy of Sciences, Guangzhou 510640, China
}

\section{H I G H L I G H T S}

- Carbonaceous particulate matter emission factors among $20 \mathrm{coal} / \mathrm{stove}$ combinations.

- Dominating factors are coal maturity, burning style and stove efficiency.

- Optical attenuation cross-section for fresh coal smoke can be deduced as $6.47 \mathrm{~m} 2 / \mathrm{g}$.

\section{A R T I C L E I N F O}

\section{Article history:}

Received 17 November 2014

Received in revised form

4 March 2015

Accepted 9 March 2015

Available online 11 March 2015

\section{Keywords:}

Emission factor

Experimental measurement

Fine particle

Black carbon

Elemental carbon

Residential coal combustion

\begin{abstract}
A B S T R A C T
As follow-up efforts for measurements on emission factors (EFs) of fine particulate matter $\left(\mathrm{PM}_{2.5}\right)$ and its carbonaceous fractions for China's household coal stoves, a large-sized dilution sampling system was designed to test a total of $20 \mathrm{coal} /$ stove combinations, which involve five coals with wide-ranged geological maturities and three stoves. Coal smoke was simultaneously collected onto quartz filter for organic carbon (OC) and elemental carbon (EC) analyses by thermal-optical reflectance (TOR) protocol and monitored online for optical black carbon (BC) by Aethalometer. The mean EFs based on burned fuel weight of $\mathrm{PM}_{2.5}, \mathrm{OC}$, EC, and $\mathrm{BC}$ are $4.25 \pm 2.45,1.11 \pm 0.72,1.43 \pm 1.17$, and $0.60 \pm 0.42 \mathrm{~g} / \mathrm{kg}$ for bituminous coal, and $1.44 \pm 0.67,0.05 \pm 0.02,0.04 \pm 0.02$, and $0.01 \pm 0.01 \mathrm{~g} / \mathrm{kg}$ for anthracite, respectively. Significant differences are observed among the EFs for various coal/stove combinations, which are attributable to the differences of coal maturity, burning style and stove efficiency. Although the EFs of BC and EC are closely correlated $(\mathrm{r}=0.97)$, the average $\mathrm{BC} / \mathrm{EC}$ ratio is only 0.39 , indicating a significant gap between the two methods; and the optical attenuation cross-section $(\sigma)$ for fresh coal smoke can be deduced as $6.47 \mathrm{~m}^{2} / \mathrm{g}$, much lower than the manufacturer's preset value of $16.6 \mathrm{~m}^{2} / \mathrm{g}$ for Aethalometer.
\end{abstract}

(c) 2015 Elsevier Ltd. All rights reserved.

\section{Introduction}

Household stoves burning solid fuels (i.e., coal and biofuel) in China have been the subject of interest in recent years because they are important emission sources of various pollutants, including fine

\footnotetext{
* Corresponding author. Key Laboratory of Coastal Environmental Processes and Ecological Remediation, Yantai Institute of Coastal Zone Research, Chinese Academy of Sciences, 17 Chunhui Road, Laishan District, Yantai, Shandong 264003, China.

** Corresponding author. Institute of Environmental Pollution and Health, School of Environmental and Chemical Engineering, Shanghai University, Shanghai 200444, China.

E-mail addresses: cgtian@yic.ac.cn (C. Tian), fengyanli@shu.edu.cn (Y. Feng).
}

particulate matter $\left(\mathrm{PM}_{2.5}\right)$, organic carbon (OC), black carbon (BC), greenhouse gases (GHGs), and toxic organic compounds such as polycyclic aromatic hydrocarbons (PAHs), etc (Bond et al., 2004a; Lei et al., 2011; Ohara et al., 2007; Shen et al., 2013b; Streets et al., 2003; Wang et al., 2012; Zhang et al., 2009). Among these pollutants, BC is especially highlighted by governments and scientists for a variety of reasons (Bond et al., 2013). First, China is considered the largest contributor to global BC burden. It was estimated that about $20 \%$ of global BC was contributed by China (Bond et al., 2004b) in which about 28\% was emitted from household stoves for coal combustion (Wang et al., 2012). Second, these great amounts of $\mathrm{BC}$ emissions have been widely linked to the 
variation of precipitation trends in eastern China and the melting of Himalayas snowpack and glaciers over the past several decades, the significant reduction of visibility in northern China, and increased occurrence of serious haze events in eastern and northern China, etc (Menon et al., 2002; Ramanathan and Carmichael, 2008; Ramanathan et al., 2007; Xu et al., 2009). Third, these fine BC particles together with some adsorbed OC (e.g., PAHs) were considered as the largest single environmental risk factor for illhealth due to indoor air pollution in China (Zhang and Smith, 2007). This inspired a number of studies on the measurements about emission factor (EF) of BC for coal combustion in household stoves in China in the last decade, which is important data for assessing its emission inventory (Bond et al., 2004a; Cao et al., 2006; Lei et al., 2011; Ohara et al., 2007; Streets et al., 2003, 2001; Wang et al., 2012; Zhang et al., 2009). Those studies show variation up to several orders of magnitude of EFs of BC and other pollutants among different coal/stove combinations in China's household sector (Chen et al., 2005, 2006, 2009; Shen et al., 2013b; Shen et al., 2010; Zhang et al., 2000, 2008; Zhi et al., 2008).

The variability is attributed to the selection of coal type, burning style of coal, stove efficiency, as well as the measurement method of carbonaceous fractions. Firstly, coal maturity is the dominant factor although it was not taken into account in most previous experiments.(Chen et al., 2009) Secondly, most reported EF data of $\mathrm{BC}$ and $\mathrm{OC}$ were derived from the thermal-optical analysis (TOA) protocols, either thermal-optical transmittance (TOT) or thermal-optical reflectance (TOR), regardless of the significant difference between the two methods.(Zhi et al., 2011) And more importantly, thermally defined elemental carbon (EC) was usually considered as an equivalent to optical BC in the calculation of emission factor and emission inventory, although there may be a great difference between the two "BC" datasets based on different definitions (Chen et al., 2005; Hammes et al., 2007; Shen et al., 2013c).

In the present experiments for household coal combustion, a large-sized dilution sampling system with particle samplers and online monitors was employed. Therefore, filter-based OC and EC data by TOA and optical BC values by a portable Aethalometer were acquired simultaneously, providing a chance to look into the relationship between $\mathrm{EF}_{\mathrm{EC}}$ and $\mathrm{EF}_{\mathrm{BC}}$ in emission inventory. Furthermore, five coals covering a wide range of maturity and three stoves of different efficiencies are carefully selected in the measurements based on our previous studies (Chen et al., 2005, $2006,2009)$. Briefly, the objectives of this study are: (1) to present a new batch of database of EFs of concerned pollutants for 20 coal/stove combinations in China, taking into account the effects of coal maturity, burning style (coal briquette versus chunk), and stove efficiency, and (2) to compare the data of thermal-optical EC and optical BC, and discuss their interchangeability for coal smoke aerosols.

\section{Materials and methods}

\subsection{Coals and stoves tested}

Twenty coal/stove combinations were tested in this study. The combinations are comprised of five coals and three commercial stoves. Our selection was based on the widest possible range of \%C and vitrinite reflectance $\left(R_{0}\right)$ to obtain the widest range in coal maturity. The $R_{0}$ is a coal-petrographic parameter that is the most commonly used to describe the maturity of a coal (Cornelissen and Gustafsson, 2004). As shown in Table 1, the five coals include one high-volatile bituminous coal (HVB, Yu-lin coal, YL), two mediumvolatile bituminous coals (MVB, Ci-xian coal, CX and Zhong-yang coal, ZY), one low-volatile bituminous coal (LVB, Chang-zhi coal, $\mathrm{CZ}$ ), and one subanthracite (SA, An-yang coal, AY) according to ASTM standard classification of coals (ASTM, 2004). Each coal was burned in both honeycomb briquette and chunk styles. The shape of coal chunk was similar to our previous studies $(3-5 \mathrm{~cm}$ in diameter), while the size of honeycomb briquette was 2.3 times larger than those used previously (Chen et al., 2005, 2006, 2009). These larger briquettes are usually consumed in northern China, shaped in 16hole columns, $8 \mathrm{~cm}$ in height and $12.5 \mathrm{~cm}$ in diameter. We prepared briquettes of each coal in a factory located in suburban Beijing, China to ensure these briquettes to be similar to those used in local residents. The preparation of coal briquettes involves pulverizing raw coal chunk to powder, combining clay with coal powder to obtain clay-powder mixture (about 2:1 for bituminous coals and 1:1 for anthracite) and pressing the mixture into honeycomb briquettes by a machine (Bond et al., 2002; Chen et al., 2005).

The three tested stoves include a traditional and simple stove (named Gan-chai stove, GC), and two technically improved stoves (Sheng-chang stove, SC and Xuan-feng stove, XF). The three types of stove are extensively used in rural and suburban household. GC stove was purchased in Anyang, Henan province, and the two technically improved stoves (SC and XF) were purchased in suburban Beijing. Traditionally, GC stove uses coal chunk as fuels, while $\mathrm{XF}$ stove uses honeycomb briquette because the stove has a helical inner wall and half-way in-draft holes, which favor ventilation during coal burning. SC stove can use the two coal styles. These three stoves are usually connected with heating systems for $30-50 \mathrm{~m}^{2}$ residence heating. The photos of these stoves are

Table 1

Analytical values of the five coals tested in both raw chunks and honeycomb briquettes.

\begin{tabular}{|c|c|c|c|c|c|}
\hline & YL & $\mathrm{CX}$ & $\mathrm{ZY}$ & $\mathrm{CZ}$ & AY \\
\hline \multicolumn{6}{|l|}{ Raw Coal Chunk } \\
\hline Rank & HVB & MVB & MVB & LVB & SA \\
\hline Vitrinite reflectance $\left(\mathrm{R}_{\mathrm{O}}, \%\right)$ & 0.72 & 1.00 & 1.50 & 1.90 & 2.47 \\
\hline Moisture $\left(\mathrm{M}_{\mathrm{ad}}, \%\right)$ & 6.45 & 0.25 & 0.58 & 0.44 & 1.75 \\
\hline $\operatorname{Ash}\left(A_{d}, \%\right)$ & 8.35 & 9.67 & 6.32 & 7.60 & 10.31 \\
\hline Volatile $\left(\mathrm{V}_{\mathrm{daf}}, \%\right)$ & 37.3 & 30.1 & 24.6 & 16.00 & 8.1 \\
\hline C, \% & $72.0 \pm 0.4$ & $70.1 \pm 0.1$ & $80.4 \pm 0.2$ & $79.0 \pm 0.2$ & $80.4 \pm 0.3$ \\
\hline $\mathrm{H}, \%$ & $4.64 \pm 0.01$ & $4.05 \pm 0.0$ & $4.66 \pm 0.03$ & $4.09 \pm 1.14$ & $3.32 \pm 0.01$ \\
\hline $\mathrm{N}, \%$ & $0.85 \pm 0.01$ & $1.19 \pm 0.01$ & $1.45 \pm 0.01$ & $1.53 \pm 0.41$ & $1.39 \pm 0.01$ \\
\hline $\mathrm{S}, \%$ & $0.48 \pm 0.12$ & $0.47 \pm 0.10$ & $1.25 \pm 0.01$ & $0.46 \pm 0.12$ & $0.27 \pm 0.02$ \\
\hline \multicolumn{6}{|l|}{ Honeycomb Coal Briquette } \\
\hline Clay mixed, \% & 33.3 & 33.3 & 30.9 & 32.3 & 50.0 \\
\hline C, \% & $47.6 \pm 0.8$ & $44.3 \pm 0.1$ & $57.6 \pm 0.3$ & $52.3 \pm 1.4$ & $45.6 \pm 1.6$ \\
\hline $\mathrm{H}, \%$ & $3.20 \pm 0.03$ & $2.77 \pm 0.00$ & $3.46 \pm 0.02$ & $2.88 \pm 0.06$ & $2.08 \pm 0.03$ \\
\hline $\mathrm{N}, \%$ & $0.63 \pm 0.02$ & $0.79 \pm 0.00$ & $1.04 \pm 0.01$ & $0.95 \pm 0.02$ & $0.81 \pm 0.03$ \\
\hline$S, \%$ & $0.24 \pm 0.01$ & $0.17 \pm 0.01$ & $1.10 \pm 0.01$ & $0.29 \pm 0.00$ & $0.09 \pm 0.01$ \\
\hline
\end{tabular}




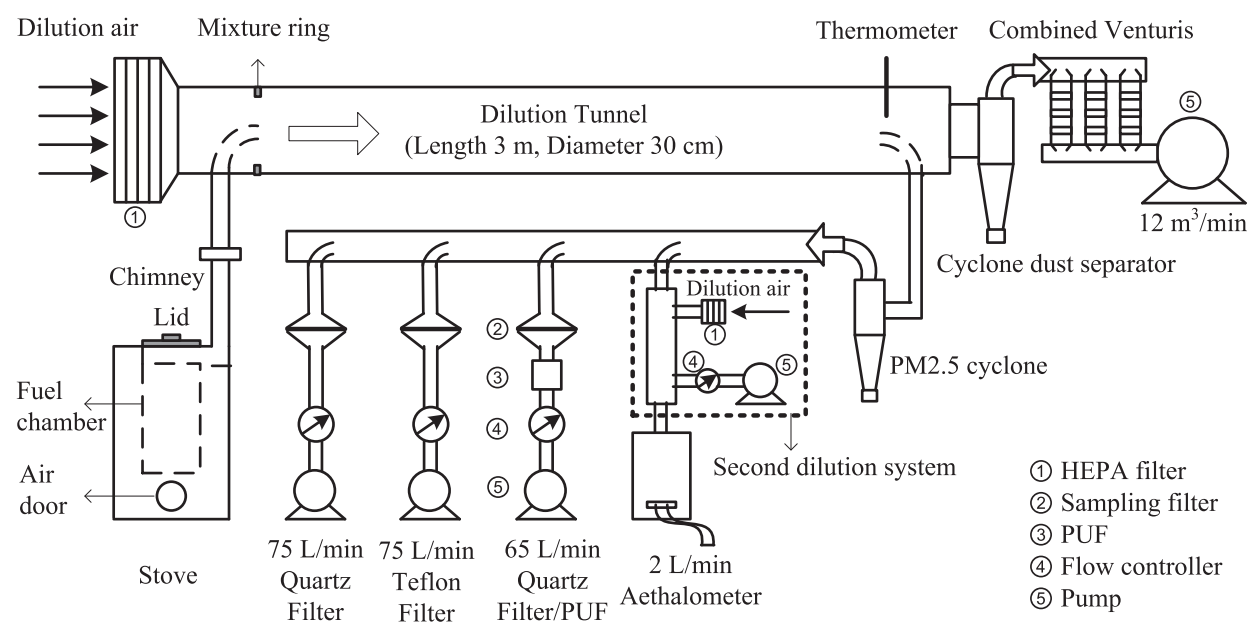

Fig. 1. Schematic diagram of the full-flow dilution sampling system.

illustrated in Figure S1 in the Supporting Information.

\subsection{Full-flow dilution sampling system}

A large-sized, stationary full-flow dilution tunnel and fractional sampling system was employed for this study. This system has been originally designed to test automobile exhaust and the reliability in dilution and operation has been validated (Wang et al., 2005). In order to accommodate the relatively low flowrate but high concentration of smokes from household stoves, the parts for smoke collection and dilution were modified. As shown in Fig. 1, the dilution tunnel system is comprised of four main parts: (1) a pipe ducting the smoke from stove chimney into the tunnel, (2) a set of high efficiency (HEPA) filters presenting particle-free air for smoke dilution, (3) a seamless stainless-metal tunnel ( $3 \mathrm{~m}$ in length and $30 \mathrm{~cm}$ in diameter), and inside it a mixing ring installed to keep the smoke diluted evenly (with Reynolds number larger than 10,000), and (4) at the end of the tunnel a pump drawing mixture flow through the tunnel at a preset flowrate $\left(12 \mathrm{~m}^{3} / \mathrm{min}\right.$ in this experiment) which is controlled accurately by a venturi assembly upstream the pump. Near the end of the tunnel, a fractional stream of dilution smoke is drawn to the sampling system.

The modified sampling system consisted of a $\mathrm{PM}_{2.5}$ cyclone, three filter samplers and a secondary dilution system for online BC monitoring. The first filter sampler collected smoke particles onto a quartz filter ( $90 \mathrm{~mm}$ in diameter) at flowrate of $75 \mathrm{~L} / \mathrm{min}$ for TOA carbon analysis, the second one collected particle onto a Teflon filter at $75 \mathrm{~L} / \mathrm{min}$ for particle weighting and inorganic analysis, and the third sampler collected particles and gaseous organics to a combination of quartz filter and PUF (polyurethane foam) at $65 \mathrm{~L} /$ min for organic compound determination. These samplers got fractional ratios of about $5 \%$. The secondary dilution system was designed especially for the Aethalometer (Magee Scientific Inc., USA) due to its relatively narrow range of real-time BC observation. This system consisted of a pump working at a flowrate of $20 \mathrm{~L} / \mathrm{min}$, an air-clean filter set, a flowmeter, and a portable Aethalometer (AE-42), and presented an additional dilution of 10 times to ensure that one deposition spot on the filter tape could last for one whole combustion experiment (Fig. 1).

\subsection{Smoke collection and analysis}

The emission sampling procedure was similar to that described previously (Chen et al., 2005) and will be briefly summarized here. Firstly, one or two anthracite honeycomb briquettes with lower EF values than AY briquettes (purchased from the market of Beijing) were ignited outdoor using small wood chips, and the coals were moved into the stove in order to heat up the inner chamber to a high temperature, and then to ignite the fuel (coal chunks or honeycomb briquettes here) from the bottom. Secondly, the dilution sampling system was started at high temperature combustion stage after the exhaust phase (about 2 min before putting the weighted coal into the stove). The emission of anthracite briquettes contributed weakly to fine particulate matter, but the contribution for OC and EC could be neglected. The coal was burned undisturbed, and the combustion process was monitored by an Aethalometer. An additional batch of coals was put into the stove depending on the need for more combustion. Thirdly, some parameters of the AE-42 were properly set to allow for more fuel burning, including turning off the UV tunnel, adjusting maximum optical attenuation value for $\mathrm{BC}$ tunnel $(880 \mathrm{~nm})$ to the top limit, enlarging the capacity of each spot, turning down the tape advance step, and decreasing the flowrate to $2 \mathrm{~L} / \mathrm{min}$, etc. In addition to the twenty coal/stove combination samples, six additional samples respecting various coals and stoves were collected for parallel checking. Flowrate check and system clean were done before each combustion experiment.

All quartz and Teflon filters were weighed before and after sampling after a $24 \mathrm{~h}$ conditioning in temperature $\left(25^{\circ} \mathrm{C}\right)$ and relative humidity (50\%) to get the $\mathrm{PM}_{2.5}$ concentrations. Quartz filters were baked at $500{ }^{\circ} \mathrm{C}$ in Muffle furnace for $12 \mathrm{~h}$ and Teflon filters were Soxhlet extracted by dichloromethane (DCM) solvent for $24 \mathrm{~h}$ to get rid of any organic pollutants on the filters. OC, EC and TC (total carbon, the sum of OC and EC) concentrations on quartz filter samples were obtained by thermal/optical reflectance (TOR) protocol (Atmoslytic Inc. Model 2001A) (Chow et al., 2004). Optical $\mathrm{BC}$ concentrations were monitored by $\mathrm{AE}-42$ at a wavelength of $880 \mathrm{~nm}$. All these masses of $\mathrm{PM}_{2.5}$ and their carbonaceous fractions on the filters, together with the fractional ratios of the samplers and fuel weight burned, were used to calculate their EF values. The mass of $\mathrm{PM}_{2.5}$ and their carbonaceous fractions emitted by anthracite used to heat up inner chamber was subtracted before the EF calculation. The ash content in raw coal and the unburned coal after combustion were not included in the calculation. Arithmetical mean of calculated EFs was used for discussion later.

\section{Results and discussion}

\subsection{Emission factors of $P M_{2.5}$ and $T C$}

EFs of $\mathrm{PM}_{2.5}$, OC, EC and TC for household coal burning are 
Table 2

Mean EFs of PM, TC, OC, EC, BC and their ratios for household coal combustion.

\begin{tabular}{|c|c|c|c|c|c|c|c|c|c|c|c|c|c|c|c|}
\hline & \multirow[t]{2}{*}{ Coal ID } & \multirow[t]{2}{*}{ Style } & \multicolumn{2}{|l|}{ PM } & \multicolumn{2}{|l|}{ TC } & \multirow[t]{2}{*}{ TC/PM } & \multicolumn{2}{|l|}{ OC } & \multicolumn{2}{|l|}{$\mathrm{EC}$} & \multirow[t]{2}{*}{$\mathrm{EC} / \mathrm{OC}$} & \multicolumn{2}{|l|}{$\mathrm{BC}$} & \multirow[t]{2}{*}{$\mathrm{BC} / \mathrm{EC}$} \\
\hline & & & Avg & Std & Avg & Std & & Avg & Std & Avg & Std & & Avg & Std & \\
\hline \multirow[t]{11}{*}{ Bituminous coal } & YL & Chunk & 3.75 & 0.51 & 2.38 & 0.21 & 0.63 & 0.67 & 0.06 & 1.71 & 0.15 & 2.55 & 0.76 & 0.10 & 0.45 \\
\hline & $\mathrm{CX}$ & & 6.99 & 0.80 & 3.36 & 1.02 & 0.48 & 0.98 & 0.04 & 2.38 & 1.06 & 2.43 & 0.91 & 0.39 & 0.38 \\
\hline & ZY & & 7.04 & 0.29 & 4.76 & 1.20 & 0.68 & 1.30 & 0.47 & 3.46 & 0.74 & 2.66 & 1.17 & 0.18 & 0.34 \\
\hline & $\mathrm{CZ}$ & & 1.96 & 0.19 & 0.88 & 0.30 & 0.45 & 0.27 & 0.02 & 0.61 & 0.29 & 2.26 & 0.24 & 0.09 & 0.40 \\
\hline & & Average & 4.93 & 2.73 & 2.84 & 1.63 & 0.58 & 0.80 & 0.45 & 2.04 & 1.23 & 2.55 & 0.77 & 0.4 & 0.38 \\
\hline & YL & Briquette & 3.27 & 0.26 & 2.66 & 0.22 & 0.81 & 1.99 & 0.01 & 0.67 & 0.22 & 0.34 & 0.39 & 0.21 & 0.58 \\
\hline & CX & & 4.47 & 0.56 & 3.06 & 1.67 & 0.68 & 1.76 & 0.75 & 1.30 & 0.92 & 0.74 & 0.62 & 0.44 & 0.48 \\
\hline & ZY & & 5.42 & 0.50 & 3.01 & 0.5 & 0.56 & 1.73 & 0.19 & 1.28 & 0.31 & 0.74 & 0.65 & 0.24 & 0.51 \\
\hline & $\mathrm{CZ}$ & & 1.14 & 0.15 & 0.29 & 0.03 & 0.25 & 0.22 & 0.03 & 0.07 & 0.01 & 0.32 & 0.02 & 0.01 & 0.35 \\
\hline & & Average & 3.58 & 1.89 & 2.25 & 1.44 & 0.63 & 1.42 & 0.80 & 0.83 & 0.71 & 0.58 & 0.42 & 0.37 & 0.51 \\
\hline & Total Average & & 4.25 & 2.45 & 2.55 & 1.57 & 0.60 & 1.11 & 0.72 & 1.43 & 1.17 & 1.29 & 0.60 & 0.42 & 0.42 \\
\hline \multirow[t]{3}{*}{ Anthracite } & AY & Chunk & 1.04 & 0.07 & 0.05 & 0.01 & 0.05 & 0.03 & 0.01 & 0.02 & 0.01 & 0.67 & 0.001 & 0.000 & 0.05 \\
\hline & AY & Briquette & 1.84 & 0.14 & 0.13 & 0.02 & 0.07 & 0.08 & 0.01 & 0.06 & 0.02 & 0.75 & 0.011 & 0.011 & 0.19 \\
\hline & Total Average & & 1.44 & 0.67 & 0.09 & 0.04 & 0.06 & 0.05 & 0.02 & 0.04 & 0.02 & 0.80 & 0.01 & 0.01 & 0.25 \\
\hline \multicolumn{3}{|c|}{ Average of all coals } & 3.69 & 2.48 & 2.05 & 1.71 & 0.56 & 0.90 & 0.77 & 1.15 & 1.19 & 1.28 & 0.48 & 0.45 & 0.39 \\
\hline
\end{tabular}

Note: 6 samples for PM calculation, and 4 samples for carbonaceous fraction calculation.

shown in Table 2, with the detailed information presented in Table S1 in the Supporting Information. In general, anthracite for type coals, SC stove for chunk, and XF stove for briquette show the smallest relative variability for $\mathrm{EF}$ data for $\mathrm{PM}_{2.5}\left(\mathrm{EF}_{\mathrm{PM}}\right)$ described by the ratio of mean to standard deviation as shown in Table S1. The variability is covered when the data measured from different stoves are combined (see Table 2). For each combustion means of three sets of $\mathrm{EF}_{\mathrm{PM}}$ derived from the three filter samples (two quartz filters and one Teflon membrane) are discussed here since small deviation is observed among them (see Table S1). Some variation characteristics about the $\mathrm{EF}_{\mathrm{PM}}$ values due to the different coals, burning styles and stoves are summarized as follows. First, coal's geological maturity is the most important factor affecting $\mathrm{EF}_{\mathrm{PM}}$ under household burning conditions. Specifically, bituminous coal with medium volatile content (MVB) has the highest $\mathrm{FF}_{\mathrm{PM}}$, which is higher than the value for anthracite by more than one order of magnitude. For example, $\mathrm{EF}_{\mathrm{PM}}$ is $10.3 \mathrm{~g} / \mathrm{kg}$ for $\mathrm{ZY}$ coal in chunk/GC stove while $0.31 \mathrm{~g} / \mathrm{kg}$ for $\mathrm{AY}$ in chunk/SC stove combination (see Table S1). Second, coal briquetting can decrease not only the EFPM values, but also their differences among various coals. The average $E_{P M}$ is $4.93 \mathrm{~g} / \mathrm{kg}$ for chunk but $3.58 \mathrm{~g} / \mathrm{kg}$ for briquette of bituminous coals, which means a decline of $27 \%$ due to briquetting. However, this trend is different for anthracite, higher $\mathrm{EF}_{\mathrm{PM}}$ value for briquette $(1.84 \mathrm{~g} / \mathrm{kg})$ than for chunk $(1.04 \mathrm{~g} / \mathrm{kg})$ is observed (see Table 2). The reasoning for this situation will be discussed below with the ratio of TC to $\mathrm{PM}_{2.5}$. Third; stove condition also significantly affects $E_{P M}$ of coal combustion. Generally speaking, the stove with higher heating efficiency generates lower $\mathrm{EF}_{\mathrm{PM}}$ values. For example, mean $\mathrm{EF}_{\mathrm{PM}}$ for the four bituminous coals in briquette style in XF stove $(2.80 \mathrm{~g} / \mathrm{kg})$ is lower than that in SC stove $(4.36 \mathrm{~g} /$ $\mathrm{kg}$ ) by more than $30 \%$ (Table S1).

For the purpose of further simplification of these emission factors, various means of $\mathrm{EF}_{\mathrm{PM}}$ of household coal burning are calculated. As shown in Table 2, $\mathrm{EF}_{\mathrm{PM}}$ for bituminous coals of both chunk and briquette styles are $4.93 \pm 2.73$ and $3.58 \pm 1.89 \mathrm{~g} / \mathrm{kg}$, while $E F_{P M}$ for anthracite of both styles are $1.04 \pm 0.07$ and $1.84 \pm 0.14 \mathrm{~g} / \mathrm{kg}$, respectively. Compared with our previous results (Table S2), the present $\mathrm{EF}_{\mathrm{PM}}$ values for bituminous coals are lower, especially for raw chunk style. For example, Zhi et al. reported average EFPM values of $13.2 \pm 13.7$ and $5.68 \pm 3.62 \mathrm{~g} / \mathrm{kg}$ for seven bituminous coals in chunk and briquette styles, respectively (Zhi et al., 2008). The obvious higher efficiencies for the stoves in this study may be responsible for these differences. Furthermore, mean $\mathrm{EF}_{\mathrm{PM}}$ values of $4.25 \pm 2.45$ and $1.44 \pm 0.67 \mathrm{~g} / \mathrm{kg}$ are suggested for bituminous and anthracite burned in household stoves, respectively, although some parameters should be taken into account when these data are applied, which include the actual percentage of each coal type (especially MVB) as well as the proportion of honeycomb briquette in use. If take no account of the impact of coal maturity, $\mathrm{EF}_{\mathrm{PM}}$ measured in the present study shows a high comparability with previous measurement results. For example, Shen et al. suggested a mean $E_{P M}$ value of $3.17 \pm 4.67 \mathrm{~g} / \mathrm{kg}$ for five coals in typical household stoves (Shen et al., 2010), close to the total average of $3.69 \pm 2.48 \mathrm{~g} / \mathrm{kg}$ for all combinations in this experiment.

Specific attention should be paid to the ratio of TC to $\mathrm{PM}_{2.5}$ because it can be used to evaluate the particulate constituents together with the combustion conditions. TC is the sum of OC and EC measured by TOR protocol. As presented in Table 2, the mean $\mathrm{EF}_{\mathrm{TC}}$ of bituminous coals is $2.84 \pm 1.63 \mathrm{~g} / \mathrm{kg}$ for chunk style and $2.25 \pm 1.44 \mathrm{~g} / \mathrm{kg}$ for briquette, and $0.05 \pm 0.01 \mathrm{~g} / \mathrm{kg}$ and $0.13 \pm 0.02 \mathrm{~g} / \mathrm{kg}$ for anthracite in the two styles, respectively. The variation trends of $\mathrm{EF}_{\mathrm{TC}}$ among various coals and between two burning styles are similar to $\mathrm{EF}_{\mathrm{PM}}$, as discussed above. However, the ratio of $\mathrm{EF}_{\mathrm{TC}}$ to $\mathrm{EF}_{\mathrm{PM}}$ (refers to as $\mathrm{TC} / \mathrm{PM}_{2.5}$ ) shows different variability as follows (Table 2). (i) TC/PM ratio decreases with the decline of coal's volatile content, meaning the correlation between TC and volatile matter of coal (correlation coefficient $r=0.6$ ). (ii) The mean value of $\mathrm{TC} / \mathrm{PM}_{2.5}$ is almost equal for chunk and briquette styles of bituminous coals, but there is a larger degree of variability among the five coals in briquette $(0.25-0.81)$. (iii) The average TC/ $\mathrm{PM}_{2.5}$ ratio is 0.57 for bituminous but only 0.06 for anthracite, indicating that more than $90 \%$ of $\mathrm{PM}_{2.5}$ in anthracite burning smoke is mineral matter. Therefore, abundant clay content in briquette and higher combustion temperature for anthracite favor more $\mathrm{PM}_{2.5}$ emission from household stoves.

\subsection{Emission factors of $O C$ and $E C$}

The $\mathrm{EF}_{\mathrm{OC}}$ and $\mathrm{EF}_{\mathrm{EC}}$ values by TOR method for the 20 combinations of household coal combustion are shown in Table S1 and Table 2 by individual and mean data separately. Similar to $\mathrm{EF}_{\mathrm{PM}}$, $\mathrm{EF}_{\mathrm{OC}}$ and $\mathrm{EF}_{\mathrm{EC}}$ show very strong dependence on the coal's geological maturity. Differences of more than one order of magnitude are observed among bituminous coals with different volatile content and anthracite (MVB generates the highest EFs). Anthracite with the highest coal maturity is shown the lowest EFs because of its low volatile content which was considered as the important precursor of $\mathrm{BC}$ (Chen et al., 2009). On average, $\mathrm{EF}_{\mathrm{OC}}$ is $1.11 \pm 0.72 \mathrm{~g} / \mathrm{kg}$ and 
$0.05 \pm 0.02 \mathrm{~g} / \mathrm{kg}$ for bituminous coal and anthracite, respectively, and $\mathrm{EF}_{\mathrm{EC}}$ is $1.43 \pm 1.17 \mathrm{~g} / \mathrm{kg}$ and $0.04 \pm 0.02 \mathrm{~g} / \mathrm{kg}$ for them (Table 2). Coal's burning style is another important factor affecting its $\mathrm{EF}_{\mathrm{OC}}$ and $\mathrm{EF}_{\mathrm{EC}}$, followed by the stove's condition. For example, bituminous coals' EFOC values are $0.80 \pm 0.45 \mathrm{~g} / \mathrm{kg}$ and $1.42 \pm 0.80 \mathrm{~g} / \mathrm{kg}$ for chunk and briquette, respectively, and their $\mathrm{EF}_{\mathrm{EC}}$ are $2.04 \pm 1.23 \mathrm{~g} /$ $\mathrm{kg}$ and $0.83 \pm 0.71 \mathrm{~g} / \mathrm{kg}$ for the two burning styles, respectively.

Our previous study has explained the strong relationship between EFs of OC and EC and coal maturity under household stove conditions, (Chen et al., 2009) while the effects of burning styles will be emphasized here. Other than the impact of briquetting on the EFs of $\mathrm{PM}_{2.5}$, OC and EC discussed above, obvious different variation tendency are observed between $\mathrm{EF}_{\mathrm{OC}}$ and $\mathrm{EF}_{\mathrm{EC}}$ derived from two burning styles. As shown in Table 2, briquetting results in a significant decrease on $\mathrm{EF}_{\mathrm{EC}}$ for bituminous coals (from $2.04 \mathrm{~g} / \mathrm{kg}$ for chunks to $0.83 \mathrm{~g} / \mathrm{kg}$ for honeycomb briquettes), similar to the variation of EFPM; while $\mathrm{EF}_{\mathrm{OC}}$ presents a reverse variation, with $0.80 \mathrm{~g} / \mathrm{kg}$ for chunk and $1.42 \mathrm{~g} / \mathrm{kg}$ for briquette, which shows a dark side of the widely used "clean coal technology", because hundreds of toxic organic compounds (such as PAHs) are included in the coal smoke. In fact, the EFs of parent PAHs and their alkylated, nitrated and oxygenated derivatives show an increase tendency after the burning style changed from raw coal chunks into their honeycomb briquettes (discussed in detail in another work). The variations of EFs of $\mathrm{PM}_{2.5}$, OC and EC for anthracite also confirm this variation (Table 2). The immediate explanation for this trend of EFs may derive from the enlarged surface area of honeycomb briquette (note that its size is larger than those used in southern China by a factor of 2.3), which favors more OC emitted under smolder condition, and deserves much more research due to strong implications on indoor air pollution. This characteristic can be further depicted by the ratio of EC/OC. As shown in Table 2, mean value of EC/OC ratio is 2.48 for bituminous chunks while 0.53 for briquettes. Alternative interpretation about this significant decrease of EC/OC ratio is the possible climate benefit due to more optically scattering of coal smoke (Zhi et al., 2009). Anyway, uncertainty should be considered about the household coal smokes in either the radiative forcing estimate because of high variability of EC/OC ratio (Jacobson, 2001) or the adverse effects on environment and human health.

The average $\mathrm{EF}_{\mathrm{OC}}$ and $\mathrm{EF}_{\mathrm{EC}}$ for household coal combustion from the 20 combinations in this work are $0.90 \pm 0.77 \mathrm{~g} / \mathrm{kg}$ and $1.16 \pm 0.37 \mathrm{~g} / \mathrm{kg}$, respectively (Table 2). As shown in Table S2, the present EF values are somewhat lower than previous measurement results by our group and Zhang et al. (Chen et al., 2005, 2006, 2009; Zhang et al., 2008; Zhi et al., 2008) but higher than those by Shen et al.(Shen et al., 2010). The main reason may point to the different selection of coal types and stove conditions, which suggests that much more measurements need to be conducted by considering all kinds of typical coal/stove combinations, especially those actually used in rural kitchens (Shen et al., 2013b). For example, the average $\mathrm{EF}_{\mathrm{EC}}$ of bituminous coal briquettes from XF stove is only $40 \%$ of those from SC stove (Table S1). Another noteworthy fact is that TOT protocol was used in all previous measurements on coal smoke filter samples, and this brings into a different proportion of OC to EC compared to TOR method, although a tentative relationship between the two protocols was formulated recently (Chow et al., 2001; Zhi et al., 2011).

\subsection{Emission factors of $B C$ and its implication}

The various mean values and individual results of $\mathrm{EF}_{\mathrm{BC}}$ by optical Aethalometer method for the $20 \mathrm{coal} /$ stove combinations are shown in Table 2 and Table S1. This is the first completed dataset of $\mathrm{EF}_{\mathrm{BC}}$ with high quality for household coal combustion compared with our previous measurement, in which a "stack tester"
(Aethalometer AE90) was employed without additional smoke dilution and therefore some of coal/stove combinations could not be measured due to high concentration of BC (Zhi et al., 2008). From these tables, some variation characteristics of $\mathrm{EF}_{\mathrm{BC}}$ could be observed. First, large differences about $\mathrm{EF}_{\mathrm{BC}}$ exist among various coals. The anthracite produces significantly low $\mathrm{EF}_{\mathrm{BC}}$, with two or three orders of magnitude lower than bituminous coals. Similar to EFs of $\mathrm{PM}_{2.5}$, OC and EC, the MVB (CX or ZY) among various bituminous coals emits the highest $\mathrm{EF}_{\mathrm{BC}}$ under residential combustion conditions. The mean $\mathrm{EF}_{\mathrm{BC}}$ is $0.60 \pm 0.42 \mathrm{~g} / \mathrm{kg}$ and $0.01 \pm 0.01 \mathrm{~g} / \mathrm{kg}$ for bituminous coal and anthracite, respectively. Second, briquetting decreases the $\mathrm{EF}_{\mathrm{BC}}$ of bituminous coals by $45 \%$ averagely, from $0.77 \pm 0.40 \mathrm{~g} / \mathrm{kg}$ for chunks to $0.42 \pm 0.37 \mathrm{~g} / \mathrm{kg}$ for briquettes. Third, stove efficiency is also an important factor on $\mathrm{EF}_{\mathrm{BC}}$. For example, the average $\mathrm{EF}_{\mathrm{BC}}$ for bituminous briquettes in $\mathrm{XF}$ stove is $0.47 \mathrm{~g} / \mathrm{kg}$, compared to $0.64 \mathrm{~g} / \mathrm{kg}$ for the data in SC stove (Table S1).

The parallel measurements of online Aethalometer monitor and filter-based TOR analysis provided an opportunity to look into the relationship between optical BC and thermal-optical EC, which are usually used exchangeably (Chen et al., 2005; Shen et al., 2013b) and to further check the attenuation cross-section $(\sigma)$ of converting the light attenuation into BC concentration of Aethalometer. As shown in Table 2 and Fig. 2, a significant correlation $(r=0.97)$ is found between $\mathrm{BC}$ and $\mathrm{EC}$, indicating a strong consistency between the two methods. However, the average $\mathrm{BC} / \mathrm{EC}$ ratio is only $0.39 \pm 0.02$, which implies that the manufacturer's preset $\sigma$ value of $16.6 \mathrm{~m}^{2} / \mathrm{g}$ for atmospheric carbonaceous aerosols at the wavelength of $880 \mathrm{~nm}$ is too high for fresh coal smoke in household stoves (Hansen, 2005). If we use the TOR EC here as calibrator, this conversion constant should be $6.47 \mathrm{~m}^{2} / \mathrm{g}$ with a range of $5.82-7.12 \mathrm{~m}^{2} /$ $\mathrm{g}$ at a 95\% confidence interval for these fresh aerosols. Allen et al. suggested a TOR EC-based $\sigma$ of $12.6 \mathrm{~m}^{2} / \mathrm{g}$ (Allen et al., 1999), which is higher than our value by a factor of 2 . Shen et al., suggested the $\sigma$ value of $7.9 \mathrm{~m}^{2} / \mathrm{g}$ at $650 \mathrm{~nm}$ for primary carbonaceous particles (Shen et al., 2013a) and Bond and Bergstrom suggested the value of $7.5 \pm 1.2 \mathrm{~m}^{2} / \mathrm{g}$ at $550 \mathrm{~nm}$ after tabulation of published data (Bond and Bergstrom, 2006). The two $\sigma$ values are a little lower than our result after recalculation into the wavelength of $880 \mathrm{~nm}$. Therefore, the difference between optical BC and thermal-optical EC should be taken into account in the calculation of EFs and emission inventory at least for the fresh carbon particles from residential coal combustion.

\subsection{Future work on better estimation of EFs for household coal burning}

When the world are arguing whether $\mathrm{BC}$ is the second climate warmer after $\mathrm{CO}_{2}$ or to what degree $\mathrm{BC}$ contributes to global warming, a persuasive estimation of primary carbonaceous particle emissions on which model simulation is based is unavailable. Even

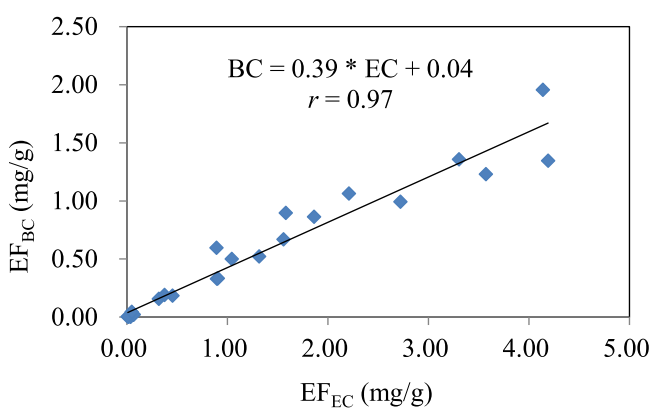

Fig. 2. The relationship between $\mathrm{EF}_{\mathrm{BC}}$ measured by Aethalometer and $\mathrm{EF}_{\mathrm{EC}}$ by TOR protocol for household coal combustion. 
the frequently cited emission inventory developed by Bond et al. (2004b) has an uncertainty of 8 times for BC, which means the top estimate is 64 times of the bottom one; this is enough to turn $\mathrm{BC}$ from an major climate modifier into a minor one. Considering that household coal combustion is the most important BC contributor in China, at least three aspects should be addressed in the future measurements about this sector. Firstly, EFs of OC and EC (or BC) are quite sensitive to coals and stove conditions selected in the experiments, so what is the "true level" of carbonaceous emissions for this sector or what is the typical percentage of each coal/stove combination? May be a comprehensive survey is needed on the residential consumption of various coals, briquette size and type (such as honeycomb briquette and coal ball) and stove efficiency. Secondly, $\mathrm{EF}_{\mathrm{BC}}$ can be measured by various measurement methods, or calculated from $\mathrm{EF}_{\mathrm{PM}}$, and yet emission inventories, published or to be published, are difficult to get all emission factors from one single method. Data inter-conversion may be a good choice between methods. Progress has been made to quantitatively link EC values measured by the two popular thermal/optical protocols, i.e., TOT versus TOR (Zhi et al., 2011). The relationship given in Fig. 2 may bridge BC and EC results for fresh coal smoke. Lastly, the changing scenario for household coal burning adds difficulty to the estimating of carbonaceous EF and emission inventory (Zhao et al., 2013). For example, the use of simple, small-sized stoves is in decline, while installation of heating-only stoves or mini-boilers is on the rise in China's rural and suburban areas. Thus, follow-up experimental measurements for new burners should be considered in the future. The efforts are helpful for the development of high resolution emission inventory in China (Fu et al., 2013).

\section{Conclusion}

Based on a large-sized dilution sampling system, emission factors of $\mathrm{PM}_{2.5}$ and carbonaceous constituents were measured for 20 household coal/stove combinations covering five coals and three stoves. Coal smokes were analyzed for EC and OC by TOR protocol and also monitored online for $\mathrm{BC}$ by Aethalometer. The mean EFs of $\mathrm{PM}_{2.5}$, OC, EC, and BC are $4.25 \pm 2.45,1.11 \pm 0.72,1.43 \pm 1.17$, and $0.60 \pm 0.42 \mathrm{~g} / \mathrm{kg}$ for bituminous coal, and $1.44 \pm 0.67,0.05 \pm 0.02$, $0.04 \pm 0.02$, and $0.01 \pm 0.01 \mathrm{~g} / \mathrm{kg}$ for anthracite, respectively. Differences observed among the EFs for various coal/stove combinations are explained by the differences of coal maturity, burning style and stove efficiency. Good correlation between the EFs of BC and $\mathrm{EC}$ are observed $(\mathrm{r}=0.97)$, while the average $\mathrm{BC} / \mathrm{EC}$ ratio is only 0.39 , indicating the optical attenuation cross-section $(\sigma)$ for Aethalometer should be adjusted to $6.47 \mathrm{~m}^{2} / \mathrm{g}$ for fresh coal smoke to bridge the gap between the two methods.

\section{Acknowledgments}

This work is fund by Strategic Priority Research Programs of CAS (XDB05030303, XDA05100402), National Natural Science Foundations of China (41473091, 41173098, 41173121, and 41273135).

\section{Appendix A. Supplementary data}

Supplementary data related to this article can be found at http:// dx.doi.org/10.1016/j.atmosenv.2015.03.023.

\section{References}

Allen, G.A., Lawrence, J., Koutrakis, P., 1999. Field validation of a semi-continuous method for aerosol black carbon (aethalometer) and temporal patterns of summertime hourly black carbon measurements in southwestern PA. Atmos. Environ. 33, 817-823.

ASTM, 2004. Standard Classification of Coals by Rank (West Conshohocken).
Bond, T., Venkataraman, C., Masera, O., 2004a. Global atmospheric impacts of residential fuels. Energy Sustain. Dev. 8, 20-32.

Bond, T.C., Bergstrom, R.W., 2006. Light absorption by carbonaceous particles: an investigative review. Aerosol. Sci. Technol. 40, 27-67.

Bond, T.C., Covert, D.S., Kramlich, J.C., Larson, T.V., Charlson, R.J., 2002. Primary particle emissions from residential coal burning: optical properties and size distributions. J. Geophys. Res. Atmos. 107, 8347.

Bond, T.C., Doherty, S.J., Fahey, D.W., Forster, P.M., Berntsen, T., DeAngelo, B.J., Flanner, M.G., Ghan, S., Kärcher, B., Koch, D., Kinne, S., Kondo, Y., Quinn, P.K., Sarofim, M.C., Schultz, M.G., Schulz, M., Venkataraman, C., Zhang, H., Zhang, S. Bellouin, N., Guttikunda, S.K., Hopke, P.K., Jacobson, M.Z., Kaiser, J.W., Klimont, Z., Lohmann, U., Schwarz, J.P., Shindell, D., Storelvmo, T., Warren, S.G., Zender, C.S., 2013. Bounding the role of black carbon in the climate system: a scientific assessment. J. Geophys. Res. Atmos. 118, 5380-5552.

Bond, T.C., Streets, D.G., Yarber, K.F., Nelson, S.M., Woo, J.-H., Klimont, Z., 2004b. A technology-based global inventory of black and organic carbon emissions from combustion. J. Geophys. Res. Atmos. 109, D14203.

Cao, G., Zhang, X., Zheng, F., 2006. Inventory of black carbon and organic carbon emissions from China. Atmos. Environ. 40, 6516-6527.

Chen, Y., Sheng, G., Bi, X., Feng, Y., Mai, B., Fu, J., 2005. Emission factors for carbonaceous particles and polycyclic aromatic hydrocarbons from residential coal combustion in China. Environ. Sci. Technol. 39, 1861-1867.

Chen, Y., Zhi, G., Feng, Y., Fu, J., Feng, J., Sheng, G., Simoneit, B.R.T., 2006. Measurements of emission factors for primary carbonaceous particles from residential raw-coal combustion in China. Geophys. Res. Lett. 33, L20815.

Chen, Y., Zhi, G., Feng, Y., Liu, D., Zhang, G., Li, J., Sheng, G., Fu, J., 2009. Measurements of black and organic carbon emission factors for household coal combustion in China: implication for emission reduction. Environ. Sci. Technol. 43, 9495-9500.

Chow, J.C., Watson, J.G., Chen, L.W.A., Arnott, W.P., Moosmüller, H., Fung, K., 2004. Equivalence of elemental carbon by thermal/optical reflectance and transmittance with different temperature protocols. Environ. Sci. Technol. 38, 4414-4422.

Chow, J.C., Watson, J.G., Crow, D., Lowenthal, D.H., Merrifield, T., 2001. Comparison of IMPROVE and NIOSH carbon measurements. Aerosol. Sci. Technol. 34, 23-34.

Cornelissen, G., Gustafsson, Ö., 2004. Importance of unburned coal carbon, black carbon, and amorphous organic carbon to phenanthrene sorption in sediments. Environ. Sci. Technol. 39, 764-769.

Fu, X., Wang, S., Zhao, B., Xing, J., Cheng, Z., Liu, H., Hao, J., 2013. Emission inventory of primary pollutants and chemical speciation in 2010 for the Yangtze River Delta region, China. Atmos. Environ. 70, 39-50.

Hammes, K., Schmidt, M.W.I., Smernik, R.J., Currie, L.A., Ball, W.P., Nguyen, T.H., Louchouarn, P., Houel, S., Gustafsson, Ö., Elmquist, M., Cornelissen, G., Skjemstad, J.O., Masiello, C.A., Song, J., Peng, P.a., Mitra, S., Dunn, J.C. Hatcher, P.G., Hockaday, W.C., Smith, D.M., Hartkopf-Fröder, C., Böhmer, A., Lüer, B., Huebert, B.J., Amelung, W., Brodowski, S., Huang, L., Zhang, W., Gschwend, P.M., Flores-Cervantes, D.X., Largeau, C., Rouzaud, J.-N., Rumpel, C., Guggenberger, G., Kaiser, K. Rodionov, A., Gonzalez-Vila, F.J., GonzalezPerez, J.A., de la Rosa, J.M., Manning, D.A.C., López-Capél, E., Ding, L., 2007. Comparison of quantification methods to measure fire-derived (black/ elemental) carbon in soils and sediments using reference materials from soil, water, sediment and the atmosphere. Glob. Biogeochem. Cycles 21, GB3016.

Hansen, A., 2005. The Aethalometer. Magee Scientific Company, Berkeley, California, CA, pp. $1-209$.

Jacobson, M.Z., 2001. Strong radiative heating due to the mixing state of black carbon in atmospheric aerosols. Nature 409, 695-697.

Lei, Y., Zhang, Q., He, K.B., Streets, D.G., 2011. Primary anthropogenic aerosol emission trends for China, 1990-2005. Atmos. Chem. Phys. Discuss. 11, 931-954.

Menon, S., Hansen, J., Nazarenko, L., Luo, Y., 2002. Climate effects of black carbon aerosols in China and India. Science 297, 2250-2253.

Ohara, T., Akimoto, H., Kurokawa, J., Horii, N., Yamaji, K., Yan, X., Hayasaka, T., 2007. An Asian emission inventory of anthropogenic emission sources for the period 1980-2020. Atmos. Chem. Phys. Discuss. 7, 4419-4444.

Ramanathan, V., Carmichael, G., 2008. Global and regional climate changes due to black carbon. Nat. Geosci. 1, 221-227.

Ramanathan, V., Ramana, M.V., Roberts, G., Kim, D., Corrigan, C., Chung, C., Winker, D., 2007. Warming trends in Asia amplified by brown cloud solar absorption. Nature 448, 575-578.

Shen, G., Chen, Y., Wei, S., Fu, X., Zhu, Y., Tao, S., 2013a. Mass absorption efficiency of elemental carbon for source samples from residential biomass and coal combustions. Atmos. Environ. 79, 79-84.

Shen, G., Tao, S., Wei, S., Chen, Y., Zhang, Y., Shen, H., Huang, Y., Zhu, D., Yuan, C., Wang, H., Wang, Y., Pei, L., Liao, Y., Duan, Y., Wang, B., Wang, R., Lv, Y., Li, W., Wang, X., Zheng, X., 2013b. Field measurement of emission factors of PM, EC, OC, parent, nitro-, and oxy- polycyclic aromatic hydrocarbons for residential briquette, coal cake, and wood in rural Shanxi, China. Environ. Sci. Technol. 47, 2998-3005

Shen, G., Yang, Y., Wang, W., Tao, S., Zhu, C., Min, Y., Xue, M., Ding, J., Wang, B., Wang, R., Shen, H., Li, W., Wang, X., Russell, A.G., 2010. Emission factors of particulate matter and elemental carbon for crop residues and coals burned in typical household stoves in China. Environ. Sci. Technol. 44, 7157-7162.

Shen, H., Huang, Y., Wang, R., Zhu, D., Li, W., Shen, G., Wang, B., Zhang, Y., Chen, Y. Lu, Y., Chen, H., Li, T., Sun, K., Li, B., Liu, W., Liu, J., Tao, S., 2013c. Global atmospheric emissions of polycyclic aromatic hydrocarbons from 1960 to 2008 and 
future predictions. Environ. Sci. Technol. 47, 6415-6424.

Streets, D.G., Bond, T.C., Carmichael, G.R., Fernandes, S.D., Fu, Q., He, D., Klimont, Z. Nelson, S.M., Tsai, N.Y., Wang, M.Q., Woo, J.H., Yarber, K.F., 2003. An inventory of gaseous and primary aerosol emissions in Asia in the year 2000. J. Geophys. Res. Atmos. 108, 8809.

Streets, D.G., Gupta, S., Waldhoff, S.T., Wang, M.Q., Bond, T.C., Yiyun, B., 2001. Black carbon emissions in China. Atmos. Environ. 35, 4281-4296.

Wang, R., Tao, S., Wang, W., Liu, J., Shen, H., Shen, G., Wang, B., Liu, X., Li, W., Huang, Y., Zhang, Y., Lu, Y., Chen, H., Chen, Y., Wang, C., Zhu, D., Wang, X., Li, B. Liu, W., Ma, J., 2012. Black carbon emissions in China from 1949 to 2050. Environ. Sci. Technol. 46, 7595-7603.

Wang, W., Hu, Y., Liu, H., Qu, T., 2005. Full-flow dilution tunnel sampling system for particulate matters from vehide emission- its interategration, flowrate control and adjustment (in Chinese). Environ. Monit. China 21, 13-17.

Xu, B., Cao, J., Hansen, J., Yao, T., Joswia, D.R., Wang, N., Wu, G., Wang, M., Zhao, H. Yang, W., Liu, X., He, J., 2009. Black soot and the survival of Tibetan glaciers. Proc. Natl. Acad. Sci. 106, 22114-22118.

Zhang, J., Smith, K.R., Ma, Y., Ye, S., Jiang, F., Qi, W., Liu, P., Khalil, M.A.K., Rasmussen, R.A., Thorneloe, S.A., 2000. Greenhouse gases and other airborne pollutants from household stoves in China: a database for emission factors. Atmos. Environ. 34, 4537-4549.

Zhang, J.J., Smith, K.R., 2007. Household air pollution from coal and biomass fuels in
China: measurements, health impacts, and interventions. Environ. Health Perspect. $115,848-855$.

Zhang, Q., Streets, D.G., Carmichael, G.R., He, K.B., Huo, H., Kannari, A., Klimont, Z., Park, I.S., Reddy, S., Fu, J.S., Chen, D., Duan, L., Lei, Y., Wang, L.T., Yao, Z.L., 2009. Asian emissions in 2006 for the NASA INTEX-B mission. Atmos. Chem. Phys. Discuss. 9, 5131-5153.

Zhang, Y., Schauer, J.J., Zhang, Y., Zeng, L., Wei, Y., Liu, Y., Shao, M., 2008. Characteristics of particulate carbon emissions from real-world Chinese coal combustion. Environ. Sci. Technol. 42, 5068-5073.

Zhao, B., Wang, S., Wang, J., Fu, J.S., Liu, T., Xu, J., Fu, X., Hao, J., 2013. Impact of national NOx and SO2 control policies on particulate matter pollution in China. Atmos. Environ. 77, 453-463.

Zhi, G., Chen, Y., Feng, Y., Xiong, S., Li, J., Zhang, G., Sheng, G., Fu, J., 2008. Emission characteristics of carbonaceous particles from various residential coal-stoves in China. Environ. Sci. Technol. 42, 3310-3315.

Zhi, G., Chen, Y., Sun, J., Chen, L., Tian, W., Duan, J., Zhang, G., Chai, F., Sheng, G., Fu, J., 2011. Harmonizing aerosol carbon measurements between two conventional thermal/optical analysis methods. Environ. Sci. Technol. 45, 2902-2908.

Zhi, G., Peng, C., Chen, Y., Liu, D., Sheng, G., Fu, J., 2009. Deployment of coal briquettes and improved stoves: possibly an option for both environment and climate. Environ. Sci. Technol. 43, 5586-5591. 